
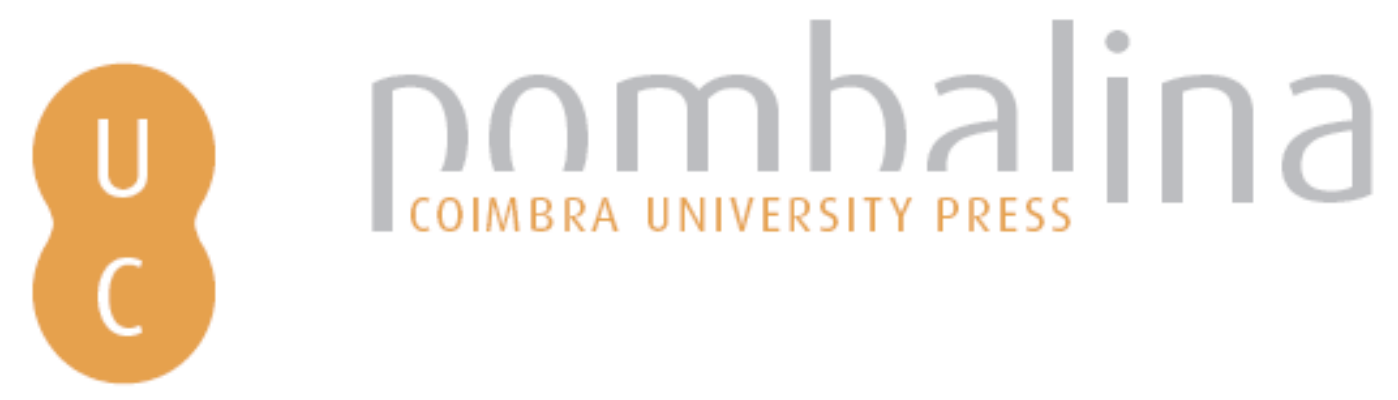

\title{
Noite, oportunidades e inovação no território: os eventos culturais à noite como expressão social do lazer
}

\author{
Autor(es): $\quad$ Almeida, Diana; Alves, Teresa \\ Publicado por: Imprensa da Universidade de Coimbra \\ URL \\ persistente: URI:http://hdl.handle.net/10316.2/30770 \\ DOI: $\quad$ DOl:http://dx.doi.org/10.14195/978-989-26-0244-8_16 \\ Accessed : $\quad$ 26-Apr-2023 11:29:09
}

A navegação consulta e descarregamento dos títulos inseridos nas Bibliotecas Digitais UC Digitalis, UC Pombalina e UC Impactum, pressupõem a aceitação plena e sem reservas dos Termos e Condições de Uso destas Bibliotecas Digitais, disponíveis em https://digitalis.uc.pt/pt-pt/termos.

Conforme exposto nos referidos Termos e Condições de Uso, o descarregamento de títulos de acesso restrito requer uma licença válida de autorização devendo o utilizador aceder ao(s) documento(s) a partir de um endereço de IP da instituição detentora da supramencionada licença.

Ao utilizador é apenas permitido o descarregamento para uso pessoal, pelo que o emprego do(s) título(s) descarregado(s) para outro fim, designadamente comercial, carece de autorização do respetivo autor ou editor da obra.

Na medida em que todas as obras da UC Digitalis se encontram protegidas pelo Código do Direito de Autor e Direitos Conexos e demais legislação aplicável, toda a cópia, parcial ou total, deste documento, nos casos em que é legalmente admitida, deverá conter ou fazer-se acompanhar por este aviso.

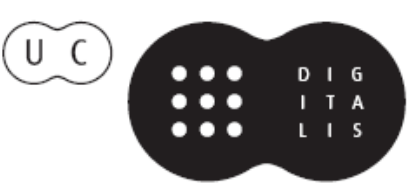




\section{TRUNFOS DE UMA}

\section{EOGRAFIA ACIVA}

\section{DESENVOLVIMENTO LOCAL,}

AMBIENTE,

ORDENAMENTO

E TECNOLOGIA

Norberto Santos

Lúcio Cunha

COORDENAÇÃO 
Diana Almeida, Teresa Alves

TERRiTUR, CEG, Instituto de Geografia e Ordenamento do Território (IGOT), Universidade de Lisboa

\author{
NOITE, OPORTUNIDADES E INOVAÇÃO NO TERRITÓRIO - OS EVENTOS CULTURAIS À \\ NOITE COMO EXPRESSÃO SOCIAL DO LAZER
}

\title{
1. INTRODUÇÃO
}

A iluminação pública começou a ser utilizada no início do século $\mathrm{XX}$, como um meio para embelezar ou dar realce aos principais monumentos ou a espaços públicos notáveis (Narboni, 2003). Apesar do investimento na iluminação, a noite continuou a ser, por muito tempo, um entrave ao desenvolvimento das actividades que se mantiveram diurnas. $\mathrm{O}$ dia e a noite pertenciam a duas realidades distintas: o dia era o palco das actividades económicas e sociais, enquanto a noite estava associada ao descanso social, ao recolher obrigatório, ao desconhecido, provocando medo, mistério, curiosidade...

O desenvolvimento das tecnologias de iluminação artificial e as mudanças sociais e culturais das últimas décadas reforçaram a importância do espaço-tempo noite em todas as esferas da sociedade e conduziram a novas práticas individuais e colectivas com reflexos na utilização dos territórios à noite. Entre os factores de mudança podemos salientar: a liberalização de costumes e práticas sociais - em consequência não só da redução da influência da religiấo, como também do crescimento dos níveis de instrução da população; as mudanças demográficas como o crescimento do número de pessoas sozinhas, sem constrangimentos de horários familiares, ou o facto de as pessoas casarem cada vez mais tarde, permanecerem mais tempo em casa dos pais, livres dos encargos associados à vida familiar; os modos de vida urbanos - que reduzem a separação entre dia e noite, entre as estaçóes do ano, e promovem ritmos de vida muito mais diversificados; a revalorizaçáo das práticas relacionadas com o tempo livre que, socialmente, deixaram de ser vistas como uma perda de tempo e passaram a constituir-se como uma mais-valia na formação dos indivíduos (Alves, 2007). As novas práticas individuais e colectivas, decorrentes destas mudanças, levam a uma profunda mudança da configuração temporal dos espaços. A organização temporal que imana da economia e dos ritmos do trabalho continua a ser determinante. As regularidades do passado transformaram-se, contudo, em ritmos, duraçóes e horários não só diversificados, como em contínua mudança. A separação entre tempo de trabalho e de não trabalho não é estável e pode variar ao longo do tempo. As alterações decorrentes de novos modos de trabalho, como por exemplo o teletrabalho e o crescimento do trabalho feminino remunerado levam a mudanças nos limites temporais, espaciais e também em termos de género, entre trabalho doméstico e trabalho remunerado (Ascher, 1997) com consequências nos usos do espaço e, em particular, nas questóes relacionadas com a 
obtenção de serviços. Mas a grande novidade das últimas décadas é o surgimento de uma nova organização temporal que surge com o desenvolvimento dos lazeres e que vem impor novas lógicas e novos constrangimentos em termos de usos do espaço (Ascher, 1997) e que valoriza do ponto vista económico e social o espaço-tempo noite (Alves, 2007).

O presente artigo encontra-se organizado em cinco partes: introdução - onde se aborda o tema da noite e as suas implicaçôes para a construção do problema; Noite dos Museus onde apresentamos a iniciativa que decorre em museus dos 47 países do Conselho da Europa; na terceira parte procedemos à caracterização dos inquiridos; na quarta parte procuramos analisar os comportamentos territoriais nocturnos dos inquiridos respondendo a um conjunto de questóes sobre as motivaçóes para saírem a noite, a interacção com o território nocturno e a receptividade a eventos que decorram à noite. Por último, apresentamos algumas conclusôes.

\section{NOITE DOS MUSEUS}

A Noite dos Museus é um evento cultural promovido desde 2005 com o patrocínio do Conselho da Europa e que decorre em simultâneo em quase todos os 47 países signatários da Convençáo Cultural do Conselho da Europa. Terry Davis, Secretário-Geral do Conselho da Europa, inquirido sobre o papel da Noite dos Museus no contexto cultural europeu afirmou:

«[...] Cette initiative européenne a pour objectif d'ouvrir gratuitement les musées du coucher du soleil jusqu'à une heure du matin, dans la plupart des 47 pays européens, membres de la Convention culturelle du Conseil de l'Europe. Le Conseil de l'Europe est ravi de soutenir cet événement qui vise à attirer un nouveau public peu accoutumé à visiter un musée. Nous pensons que la culture s'adresse à tous. L'allongement des heures d'ouverture, la gratuité de l'entrée et un programme imaginatif de divertissement sont d'excellents moyens de toucher ce public plus large, en particulier les jeunes qui, en participant à cette initiative, découvriront un nouveau monde passionnant de connaissances et de richesses culturelles qui leur permettra de mieux se connaitre ou de mieux comprendre leurs parents, leurs amis ou leurs voisins.» (http://nuitdesmusees.culture.fr/index.php?l=FRA\&id=accueil/ /le-conseil-de-l-europe, 24-11-2009)

Em Portugal, à quinta edição da Noite dos Museus aderiram museus e palácios do Instituto dos Museus e da Conservação, mas também outras instituiçôes integradas na Rede Portuguesa de Museus, que associaram o evento ao Dia Internacional dos Museus subordinado ao tema Museus como Agentes de Mudança Social e Desenvolvimento. Por recomendação do Conselho Internacional de Museus (ICOM) estas iniciativas serviram também para chamar a atenção para os potenciais benefícios de uma mais eficaz articulação entre turismo e museologia. Integradas nestes eventos decorreram por todo o país mais de meio milhar de actividades: das habituais visitas guiadas, a visitas orientadas por artistas plásticos consagrados ou por especialistas como historiadores e arqueólogos, passando por concertos, representaçóes teatrais e exibiçóes de filmes, até actividades menos frequentes na programação, como sessóes de ilusionismo, provas de queijos e vinhos, mostras de gastronomia, campeonatos de xadrez, vendas de artesanato, bailes e muita animação para todas as idades (http://www.ipmuseus.pt, 20-5-2009). Algumas instituiçóes aproveitaram 
para mostrar o que de melhor fazem, mas outras apostaram em apresentar novas facetas de modo a motivarem as visitas e atrair novos públicos.

De acordo com os dados publicados no sítio do Instituto dos Museus e da Conservação, Maio tem sido, nos últimos anos, o mês com maior afluência de visitantes nas instituiçóes que aderem a estas iniciativas. Nalguns casos observa-se mesmo a quase duplicação do número de visitantes no mês de Maio quando comparado com a afluência nos meses de Abril e Junho (http://www.ipmuseus.pt, 22-10-2009).

\section{QUEM SÃO AS PESSOAS QUE PARTICIPAM NA NOITE DOS MUSEUS?}

De modo a compreenderemos quem são as pessoas que vão a eventos como a Noite dos Museus, desenvolvemos um inquérito junto de participantes de cinco Museus, localizados em Lisboa, com programaçốes diversificadas e com capacidade de atrair públicos diferentes. Foram eles: o Museu Nacional de Arte Contemporânea - Museu do Chiado, o Museu Nacional de Arqueologia, o Museu Nacional de Etnologia, o Museu Nacional de Arte Antiga e dois núcleos do Museu da Água (Mãe de Água das Amoreiras e o Aqueduto das Águas Livres em Campolide).

A programação da Noite dos Museus no Museu Nacional de Arte Contemporânea Museu do Chiado caracterizou-se por uma maratona de visitas guiadas por especialistas, espectáculos de música e um recital pela artista Lula Penha, que criaram uma animação de festa pouco habitual num espaço museológico. No Museu Nacional de Arqueologia foi possível ver, para além da inauguração de uma nova exposição, oleiros e canteiros a trabalhar, ouvir música de géneros diversos e comer pastéis de feijão de Torres Vedras e bolos típicos de Cantanhede. O Museu Nacional de Etnologia promoveu, conjuntamente com as visitas guiadas, diversas oficinas temáticas dirigidas a públicos de todas as idades $\mathrm{e}$ um baile tradicional. No Museu Nacional de Arte Antiga apresentou-se a recém-recuperada Custódia de Belém e guiaram-se visitas a outras peças da colecção (Painéis de $S$. Vicente de Fora), mas foram os concertos e um espectáculo de capoeira que conferiram originalidade à noite. O Museu da Água desenvolveu actividades nos seus diversos núcleos, mas os mais visitados foram a Mãe de Água das Amoreiras, onde as encenaçóes do que seriam os tempos de lazer da nobreza, acompanhadas de diálogos e músicas da época, sendo também permitida visitas aos jardins, ao interior e ao terraço; no Aqueduto das Águas Livres foi proposto um passeio nocturno de Campolide ao Parque Florestal de Monsanto onde, para além das explicaçóes históricas e da experiência única de poder atravessar o aqueduto desfrutando da paisagem do pôr-do-sol, foi possível passear observando a vida da fauna noctívaga do parque florestal. A visita estava limitada a 500 pessoas, mas os números foram largamente ultrapassados.

Foram inquiridos 180 indivíduos, seleccionados aleatoriamente de entre as pessoas que participaram na Noite dos Museus em Lisboa e que estavam nos espaços do evento entre as $20 \mathrm{~h}$ de dia 16 de Maio e as $02 \mathrm{~h}$ de dia 17 de Maio de 2009. Os dados da amostra mostram que as pessoas que afluíram a este evento eram sobretudo adultos jovens (dos 25 aos 45 anos representavam 56,1\%, logo seguidos pelos indivíduos com idades entre os 45 e os 65 anos, 28,3\%) que residiam no concelho de Lisboa (50\%) ou em concelhos centrais da AML (Sintra, 9,4\%; Cascais, 7,2\%; e Odivelas, 6,7\%); na maioria dos casos tinham um curso superior $(71,7 \%)$, inseriam-se no grupo das profissóes intelectuais e científicas $(43,3 \%)$ 
ou eram técnicos e profissionais de nível intermédio (21,7\%); os profissionais mais desqualificados, como operários e artífices e operadores de instalaçóes e de máquinas, representavam $2,2 \%$ e o pessoal desqualificado dos serviços representava $2,8 \%$ da amostra; os estudantes $(6,7 \%)$, os reformados $(4,4 \%)$ e os desempregados $(2,2 \%)$ eram grupos pouco relevantes.

Os amigos e familiares tinham sido o principal meio através do qual tinham tido conhecimento da iniciativa $(43,9 \%)$ e uma parte muito significativa das pessoas participavam no evento em grupo, com os amigos ou a família. Poucas eram as pessoas que estavam ali por já terem participado no evento em anos anteriores $(2,8 \%)$.

Quando questionados sobre o que iriam fazer após o evento: $60 \%$ declararam que iam para casa; $32,8 \%$ pretendiam não ir para casa, mas prolongar a noite pelas mais variadas actividades, como ir a bares $(11,1 \%)$, restaurantes $(6,1 \%)$ ou ainda ir visitar outro Museu (8,9\%). Alguns declararam que não sabiam ainda o iriam fazer (7\%) e 2,8\% das pessoas pretendiam ficar a passear pelo espaço público.

\section{COMPORTAMENTOS TERRITORIAIS À NOITE}

De acordo com as respostas ao inquérito estamos perante uma populaçáo relativamente jovem, instruída e com profissóes qualificadas, que sai com frequência à noite: $31 \%$ declararam que saíam à noite pelo menos 1 vez por semana, 26\% várias vezes por semana e $17 \%$ pelo menos 1 vez por mês. Todos os inquiridos afirmaram sair à noite por motivos de lazer, mas só $11 \%$ com o objectivo de trabalhar.

Os indivíduos que declararam sair à noite pelo menos 1 vez por semana $(31 \%$ dos inquiridos) caracterizavam-se por serem os mais jovens e os que revelavam ou maiores limitaçóes financeiras (estudantes, desempregados, profissóes menos qualificadas) ou em termos de tempo (adultos, entre os 45 e os 64 anos, activos profissionalmente e com filhos).

Os indivíduos que afirmaram sair várias vezes por semana ( $26 \%$ dos inquiridos) pertenciam aos escalóes etários entre os 25 e os 44 anos (29\%) e com 65 ou mais anos (29\%). Estas pessoas correspondem aos grupos com menores constrangimentos familiares, profissionais e, mesmo, financeiros. Os mais jovens estão, frequentemente, livres das obrigaçóes familiares, a constituição de família acontece cada vez mais tarde e, se têm emprego, os encargos ainda são reduzidos pois a instabilidade profissional não estimula a saída da segurança da casa dos pais, pelo que acabaram por dispor de maior capacidade financeira e de tempo, o que estimula as saídas à noite por motivos de lazer. Os mais idosos acabam por reunir as mesmas condiçóes porque, em geral, já não têm os filhos a cargo, a estabilidade dos rendimentos auferidos é superior e, por outro lado, menos pressionados pelos compromissos profissionais dispóem de mais tempo.

As pessoas com profissóes intelectuais/científicas e os técnicos e profissionais de nível intermédio foram os que declararam sair com maior frequência à noite, representando $43,3 \%$ e $21,7 \%$, respectivamente, do total da amostra. O grupo profissional com menor peso das saídas à noite foi o dos operários, artífices e operadores e instaladores de máquinas, precisamente os que auferem, em média, remuneraçóes mais baixas. Estes dados parecem confirmar que a disponibilidade financeira é um aspecto determinante na frequência e nos tipos de actividades desenvolvidas nas saídas à noite. 
As saídas à noite, de acordo com os dados do inquérito, relacionavam-se sobretudo com práticas de lazer, só $11 \%$ o faziam para trabalhar. As actividades de lazer mais frequentes eram, em primeiro lugar, as que fazem a ligação entre economia do divertimento e o sector agro-alimentar, onde dominavam os restaurantes ( $51 \%$ dos inquiridos), os bares $(26 \%)$ e as discotecas (11\%). Em segundo lugar, destacavam-se as actividades que articulam a economia do espectáculo e o enriquecimento cultural como o cinema (38\%), o teatro $(26 \%)$ e toda uma variedade de outros espectáculos $(29 \%)$. A ida a casa de amigos (7\%) ou o usufruto do espaço público (2\%) sem estar associado a formas de consumo que implique gastos monetários, não revelavam grande significado nas práticas de lazer.

De acordo com os dados do inquérito estes comportamentos são diversificados de acordo com os grupos etários e com o tipo de profissóes. Assim, os adultos mais jovens (25 a 44 anos) surgem mais associados às idas a bares e discotecas, espaços ou locais que os idosos (65 e mais anos) não frequentam. As idas ao cinema são de todas as práticas as que surgem menos estratificadas por idades e a que revela maior frequência de ocorrências. Pelo menos uma vez por semana, $24,4 \%$ dos inquiridos deslocam-se para ir ao cinema à noite, $12,8 \%$ para ir ao teatro e $1,4 \%$ para assistir a espectáculos. A concorrência dos outros meios, como o vídeo ou a televisão, parece náo ser um factor que afaste estas pessoas das salas de espectáculos e das saídas à noite. Estes valores reflectem o elevado nível sociocultural e económico da populaçáo que aderiu à Noite dos Museus.

Quando inquiridos sobre a frequência de visitas a museus ou similares, como palácios, galerias de arte ou centros culturais, $27 \%$ responderam que o fazem raramente, enquanto $22 \%$ disseram que vão pelo menos uma vez por mês. Cruzando esta informação com a pergunta «é a primeira vez que vem à Noite dos Museus?» verificou-se que $45 \%$ das pessoas que já tinham estado na Noite dos Museus eram visitantes frequentes de museus e similares. Enquanto $88 \%$ dos estreantes na Noite dos Museus pertenciam ao grupo que raramente frequenta este tipo de serviços. Ou seja um evento como a Noite dos Museus tem a capacidade de atrair todo o tipo de públicos, do mais informado, visitante habitual de museus, ao que só vai aos museus naquela noite específica, para $66 \%$ dos inquiridos, a ida àquela Noite dos Museus era uma novidade. Um evento como a Noite dos Museus não chega, contudo, para incentivar a prática da ida com regularidade a museus, pois $33 \%$ dos inquiridos que referiu nunca frequentar museus ou similares afirmou já ter participado em anteriores edições desta iniciativa.

Verificamos através dos dados do inquérito que a maioria dos estreantes na Noite dos Museus estava entre os indivíduos com maior assiduidade nas saídas nocturnas por lazer. $\mathrm{O}$ que é compreensível quando verificamos que o principal atractivo desta iniciativa era, para todos, independentemente da frequência com que saem habitualmente à noite, o horário alargado. O espectáculo proporcionado por este evento atraía principalmente a população com mais de 65 anos, enquanto o tipo de museu era o factor de atracção mais referido pelos mais jovens.

De acordo com os dados do inquérito o horário habitual, com encerramento às $18 \mathrm{~h}$, constituía o principal entrave a uma maior frequência das visitas, $89 \%$ dos inquiridos afirmou que iria mais vezes a Museus/Palácios, galerias de arte ou centros de exposição se estivessem abertos à noite. Assim quando inquiridos sobre quais os horários que estes serviços deveriam ter verificámos que cerca de $8 \%$ dos inquiridos sugerem entre as 18 e as $20 \mathrm{~h}, 44 \%$ entre as $20 \mathrm{~h}$ e as $22 \mathrm{~h}$ e $46 \%$ entre as $22 \mathrm{~h}$ e as $24 \mathrm{~h}$. Quanto maior a frequência das saídas nocturnas por lazer maior a apetência por horários de encerramento mais 
tardios. De modo a responder a esta procura alguns museus de Lisboa já encerram, mais tarde, um dia por semana, mas o horário não ultrapassa as $22 \mathrm{~h}$. A afluência nestes dias, de acordo com a informaçáo prestada pelas entidades gestoras dos equipamentos, depende do tipo de exposição.

Por fim procurámos saber quais os meios de deslocação utilizados e verificámos que a utilizaçấo de transporte individual associada às saídas à noite dominava - 80\% dos inquiridos deslocaram-se para a Noite dos Museus em viatura própria/familiares ou de amigos. As principais razóes invocadas para esta opçáo foram a dificuldade de conciliar os horários da saída com os dos transportes públicos e as questóes de segurança. Neste contexto, em que metade dos indivíduos da amostra residia fora da cidade de Lisboa, as deslocaçóes a pé tinham de ser pouco frequentes (apenas 12 dos 180 indivíduos). Quem se deslocou a pé foram, sobretudo, os mais jovens. A população com 65 e mais anos foi a que mais utilizou os transportes públicos. Este meio representou $13 \%$ no total dos meios de deslocação.

\section{CONCLUSÃO}

A análise dos resultados permite concluir que as pessoas inquiridas que participaram na Noite dos Museus (em Lisboa) saem à noite pelo menos uma vez por semana, independentemente do seu estatuto socioprofissional. Os que saem com maior frequência à noite por motivos de lazer são os que têm melhor situação financeira, expressa nos níveis de instrução mais elevados e nos tipos de profissôes mais qualificadas. Constituem a população activa mais jovem, com ritmos mais dessincronizados, com melhor acesso a bens culturais e sem grandes encargos familiares, em geral sem filhos. Revelam uma preferência por padróes de funcionamento dos equipamentos culturais mais tardios.

Entre as pessoas inquiridas na Noite dos Museus as saídas à noite com o objectivo de trabalhar eram pouco frequentes. O que parece compreensível pois quem sai à noite para trabalhar não terá tempo para se deslocar com grande frequência a eventos culturais nocturnos.

Para os inquiridos na Noite dos Museus o aumento da frequência com que visitam habitualmente museus ou similares dependeria sobretudo dos horários de funcionamento, sendo fundamental que passassem a estar abertos à noite. Os inquiridos procuram essencialmente um horário de funcionamento mais alargado, que lhes permitisse participar mais activamente na vida cultural e que não coincidisse com o seu horário de trabalho e que não fosse exclusivamente aos fins-de-semana. A variedade do espectáculo proporcionado e o facto de serem gratuitos são também factores de atracção que promoveriam as visitas aos museus e similares.

A interacção dos inquiridos na Noite dos Museus com o espaço público é muito variável. A maioria dos inquiridos não ia prolongar a sua saída à noite, dirigindo-se para casa. Mas, nalguns casos procuravam continuar a noite visitando outros museus inseridos na rede do evento ou dirigindo-se a restaurantes ou bares. Permanecer no espaço público, sem gastar dinheiro, era o objectivo de apenas 2,8\% dos inquiridos.

A interacção das pessoas com o evento Noite dos Museus é bastante positiva, sendo para a larga maioria algo que classificam como muito interessante e estimulador. Embora para a grande maioria, esta experiência tenha sido a primeira, a divulgação do evento fez-se 
sobretudo baseado em meios informais de comunicação, como os amigos e/ou familiares, o que demonstra ser um evento não restritivo a um grupo de espectadores assíduos ou privilegiados. Quase todos os inquiridos desejavam vir a repetir a experiência no próximo ano.

Conclui-se assim que os eventos que ocorrem à noite têm a capacidade de atrair fundamentalmente a população que trabalha. O período nocturno é aquele onde as pessoas estão menos pressionadas pelas obrigaçóes e, simultaneamente, mais disponíveis para conviver ou desfrutar de eventos culturais, funcionando como um período de tempo escolhido por si.

\section{REFERÊNCIAS BIBLIOGRÁFICAS}

Almeida, D; ALVES, T. 2009, "Planning the night - light as a central issue», in Regional Studies Association Conference Book, Leuven, Bélgica.

Ascher F. 1997, Du vivre en juste a temps au chrono-urbanisme, Les Annales de La Recherche Urbaine $\mathrm{n}^{\circ} 77, \mathrm{p}$. 113-122.

Alves, T. 2004, «Fazer Geografia através da Luz» in Luzboa, a arte da luz em Lisboa. Extramuros, Almada.

Alves, T. 2007, "A noite, a cidade e a geografia das actividades económicas», in Geophilia. O sentir e os sentidos da Geografia. Homenagem a Jorge Gaspar, ed. Centro de Estudos Geográficos, Lisboa, pp.498-500.

Alves, T. 2009, Geografia da Noite, Centro de Estudos Geográficos, Universidade de Lisboa.

Cauquelin, A. 1977, La ville la nuit, Paris, PUF.

Denzin; Lincoln 1998, The Landscape of Qualitative Research, Theories and Issues", SAGE Publications.

Espinasse; Gwiazdinski \& Heurgon 2005, La nuit en question(s), ed. de l'Aube, ESSAI.

Fachard, L. 2003, Scénographie au service de la ville, Ateliê Fazer Céus. Museu do Fado e da Guitarra, Lisboa.

Gwiazdinski L. 2003, La ville 24 heures sur 24 ed. l'Aube, Collection Monde en Cours.

Gwiazdinski L. 2005, La Nuit, derniére frontiére de la ville, ed. de l'Aube, ESSAI.

Narboni, R. 2003, «Brève histoire de l'urbanisme lumièr», in Penser la ville par la lumière, Project Urbain, ed. de la Villette, Paris.

Paquot, T. 2000, "Le sentiment de la nuit urbaine aux XIX et XX siècles», in Les Annales de la Recherche Urbaine, n.87, PUCA. 